\title{
Die Nichtöffentlichkeit des Schiedsverfahrens
}

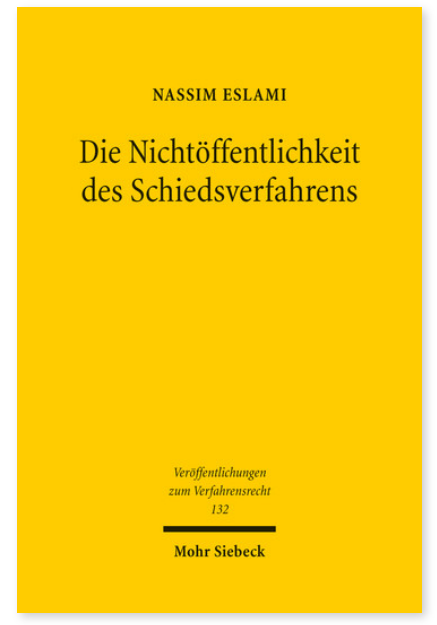

2016. XX, 459 Seiten. VVerfR 132

ISBN 978-3-16-154744-7

DOI 10.1628/978-3-16-154744-7

eBook PDF 104,00€

ISBN 978-3-16-154713-3

fadengeheftete Broschur 104,00€
Die Schiedsgerichtsbarkeit ist aus dem System der Streitbeilegungsmechanismen nicht mehr wegzudenken. Mit deren wachsender Bedeutung ist aber auch die Kritik wegen der mangelnden Transparenz der Verfahren laut geworden. Inwieweit gewährleistet die Schiedsgerichtsbarkeit tatsächlich Vertraulichkeit? Bei dieser Diskussion herrscht jedenfalls weitestgehend Einigkeit, dass die Verfahren generell unter Ausschluss der Öffentlichkeit geführt werden und auch die Schiedssprüche ohne ausdrückliche Einwilligung der Parteien nicht publiziert werden dürfen. Auf der anderen Seite wird die Schiedsgerichtsbarkeit als echte Rechtsprechung qualifiziert. Vor diesem Hintergrund widmet sich Nassim Eslami der Frage, ob für die Schiedsgerichtsbarkeit nicht ein Mindestmaß an Öffentlichkeit zwingend zu fordern ist. Die Autorin konzentriert sich auf die Handelsschiedsgerichtsbarkeit, bezieht aber auch Fragen der Investitionsschiedsgerichtsbarkeit, ausländisches Schiedsverfahrensrecht sowie zahlreiche institutionelle Schiedsordnungen mit ein. Die Arbeit schließt mit einem Gesetzgebungsvorschlag.

Nassim Eslami Geboren 1985; Studium der Rechtswissenschaft an der Leibniz Universität Hannover; Referendariat am OLG Celle; Promotionsstudium an der Universität Hannover; seit 2010 wissenschaftliche Mitarbeiterin am Lehrstuhl für Bürgerliches Recht, Deutsches, Europäisches und Internationales Zivilprozessrecht der Leibniz Universität Hannover.

Jetzt bestellen:

https://mohrsiebeck.com/buch/die-nichtoeffentlichkeit-des-schiedsverfahrens-9783161547447?no_cache=1 order@mohrsiebeck.com

Telefon: +49 (0)7071-923-17

Telefax: +49 (0)7071-51104 